\title{
Análise do Entendimento Conceitual em uma Sequência Didática sobre o Uso de Pesticidas Fundamentada na Modelagem Analógica
}

\section{Analysis of Conceptual Understanding in a Didactic Sequence about the Use of Pesticides Based on Analogical Modelling}

\author{
Adriana M. Lima e Nilmara B. Mozzer
}

Resumo: Neste trabalho investigamos como a vivência de uma sequência didática centrada na questão sociocientífica sobre o uso de pesticidas e fundamentada no processo de modelagem analógica influenciou o entendimento dos estudantes sobre o conceito de dispersão. A pesquisa foi realizada em uma turma de Química do terceiro ano do ensino médio, de uma escola pública do município de Itabirito, Minas Gerais. As aulas em que a sequência didática foi desenvolvida foram registradas em áudio e vídeo e os dados de um grupo de quatro estudantes foram analisados em um estudo de caso. Em nossa análise, identificamos alguns fatores que foram essenciais para o entendimento dos estudantes sobre o conceito de dispersão, como: o caráter colaborativo das atividades e do grupo; os questionamentos da professora e das pesquisadoras; e o uso de modelos e analogias como ferramentas de pensamento. Esses fatores justificam a importância da Modelagem Analógica no ensino de Ciências para a elaboração de entendimentos nas dimensões conceitual, procedimental e atitudinal, embora nosso enfoque no presente trabalho tenha sido sobre a primeira delas.

Palavras-chave: Questões Sociocientíficas. Modelagem Analógica. Pesticidas.

\begin{abstract}
In this paper, we investigate how the experience of a didactic sequence centered on a socio-scientific issue about the use of pesticides and based on analogical modelling process influenced the students' understanding about the concept of dispersion. The research was conducted in a third-year, high school Chemistry class of a public school of Itabirito, Minas Gerais. The classes in which the didactic sequence was developed were recorded on audio and video and data from a group of four students were examined in a case study. In our analysis, we identified some factors that were essential to the students' understanding about the concept of dispersion: the collaborative nature of the activities and of the group; the questions of the teacher/researchers; and the use of models and analogies as tools of thought. These factors justify the importance of Analogical Modelling in science education to develop understandings in the conceptual, procedural and attitudinal dimensions, although our focus in this work was on the first one.
\end{abstract}

Keywords: Socio-Scientific Issues. Analogical Modelling. Pesticides.

Adriana Moreira Lima (adrianamoreiralima@yahoo.com.br), licenciada em Química (2013) pela Universidade Federal de Ouro Preto (UFOP), é mestranda pelo Programa de Pós-graduação em Educação do Instituto de Ciências Humanas e Sociais (ICHS) da UFOP. Mariana, MG - BR. Nilmara Braga Mozzer (nilmara@ufop.edu.br), licenciada em Química (2004) pela Universidade Federal de Minas Gerais (UFMG), é mestre e doutora em Educação em Ciências pela Faculdade de Educação da UFMG. Professora do curso de Química Licenciatura da UFOP e do Programa de Pós-graduação em Educação do ICHS-UFOP. Mariana, MG - BR.

Recebido em 23/08/2018, aceito em 05/12/2018

A seção "Cadernos de Pesquisa" é um espaço dedicado exclusivamente para artigos inéditos (empíricos, de revisão ou teóricos) que apresentem profundidade teórico-metodológica, gerem conhecimentos novos para a área e contribuições para o avanço da pesquisa em Ensino de Química. 
O ensino de Ciências é impactado (ou deveria ser) pelo avanço científico e tecnológico e pelas relações deste com a sociedade. Diante disso, é necessário reconhecer a importância de se discutir letramento científico mais amplamente, pensando-se no modo como as práticas educacionais estão sendo realizadas nas escolas e propostas nos currículos de Ciências (Zeidler et al., 2005).

Autores como Sadler (2011), Mamede e Zimmermann (2005) e Santos e Mortimer (2001) vêm discutindo um letramento científico no qual todos os estudantes - e não apenas aqueles que almejam seguir uma carreira associada à ciência - sejam estimulados a confrontar e negociar ideias e tomar decisões em situações cotidianas que envolvam conhecimentos científicos.

De acordo com Mamede e Zimmermann (2005), um estudante letrado não é aquele que é capaz apenas de decodificar a linguagem da ciência, mas aquele que efetivamente faz uso do conhecimento tecnológico e científico na vida social de uma maneira mais ampla, dentro de um contexto sóciohistórico específico. Nesse mesmo sentido, Santos e Mortimer (2001) entendem letramento científico e tecnológico como a condição do indivíduo não apenas de reconhecer a linguagem científica e tecnológica, mas de cultivá-la e de fazer uso dela nas práticas sociais. No ensino de Ciências proposto a partir dessas perspectivas de letramento científico "a aprendizagemé contemplada não como uma aquisição do conhecimento, mas como um processo de participação social em que o contexto e a natureza da situação têm grande influência" (JiménezAleixandre, 2010, p. 2).

Assim, faz-se necessário incluir no currículo de Ciências debates e discussões que possam favorecer o ensino contextualizado, que tende a privilegiar a consideração e integração de diferentes dimensões, sejam estas: a social (a qual aborda as estruturas da sociedade, aspectos de convivência, bemestar, economia etc.); a política (a qual trata da interferência nos direitos e liberdades dos indivíduos que compõem uma sociedade); a ética (que diz respeito ao nível normativo, o que é considerado aceitável ou não); a ambiental (que afeta a proteção ao e melhoria do meio ambiente e recursos naturais), entre outras - na busca por contribuir para a formação de estudantes críticos e atuantes (Jiménez-Aleixandre, 2010; Silva e Marcondes, 2010).

Em consonância com esse gênero de ensino, a abordagem de Questões Sociocientíficas (QSC) mostra-se promissora. Estas são questões sociais controversas que possuem ligações científicas ou processuais com a ciência. A solução (ou soluções) dessas questões pode envolver princípios científicos, teorias e dados, mas não pode ser inteiramente determinada por considerações científicas (Sadler, 2011). Para Grace (2006) as QSC possuem algumas características comuns, como: ter base em ciência; conter um elemento de controvérsia; envolver a formação de opiniões e escolhas em nível pessoal ou social; lidar com informações incompletas devido à existência de evidências científicas conflitantes; envolver análises de custo/benefício em que o risco interage com valores; envolver a consideração do desenvolvimento sustentável; envolver valores e raciocínio ético; exigir compreensão de probabilidade e risco.

Alguns trabalhos, como os de Aikenhead (1985), Conrado (2017), Torres e Solbes (2018) e Conrado et al. (2016), destacam a importância do tratamento de QSC no ensino, no sentido de contribuir para que os estudantes se sintam motivados a debatê-las, uma vez que essas são questões que os afetam diretamente. A introdução de QSC em atividades didáticas também pode proporcionar a ampliação da compreensão do conhecimento científico pelos estudantes e o desenvolvimento de habilidades como as argumentativas, pois se espera que os mesmos sejam confrontados com problemas autênticos, ${ }^{1}$ que demandem deles a negociação de significados, o processamento de informações, o atendimento a questões morais e éticas e a adoção de uma posição sobre a questão (Sadler et al., 2004).

Jiménez-Aleixandre e Agraso (2006) definem a argumentação como a capacidade de relacionar dados e conclusões, de avaliar enunciados teóricos à luz de dados empíricos e de usar provas (ou evidências) para fundamentar um raciocínio. Nesse sentido, as situações argumentativas são inerentes à abordagem de QSC em sala de aula, uma vez que nos debates e discussões envolvendo essas questões, os estudantes precisam ser incentivados a analisar informações, confrontar, negociar e argumentar perante ideias e dados, para se posicionarem em relação a elas. Por essas razões, a argumentação em torno de QSC pode favorecer o raciocínio crítico e contribuir para a aprendizagem de Ciências, pois explicita a necessidade dos estudantes desenvolverem uma opinião - como parte de uma competência social e cívica - embasando suas afirmações em evidências e debatendo-as no contexto social (JiménezAleixandre, 2010).

A complexidade e abstração dos conceitos científicos e a dificuldade dos estudantes de relacioná-los ao seu cotidiano também realçam a importância da abordagem de questões sociocientíficas no ensino de Ciências e de ferramentas de pensamento como os modelos e as analogias. O processo de elaboração, crítica e refino de modelos e analogias é denominado modelagem analógica por autores como Nersessian (2002) e Mozzer e Justi (2018), o qual é descrito em mais detalhes na seção seguinte. Atividades de caráter colaborativo voltadas para o ensino de Ciências e fundamentadas nesse processo vêm sendo propostas e têm apresentado resultados positivos em termos da aprendizagem conceitual e de habilidades argumentativas pelos estudantes (Andrade e Mozzer, 2016; Andrade et al., 2017).

Diante disso, e considerando-se a aprendizagem como um processo social, no qual os estudantes precisam ser motivados a confrontar e negociar ideias e a utilizar ferramentas de pensamento na elaboração de significados que permeiam a discussão de questões autênticas, neste trabalho nos propusemos a investigar como a vivência da sequência didática centrada na QSC sobre o uso de pesticidas e fundamentada no 
processo de modelagem analógica influenciou o entendimento dos estudantes sobre o conceito de dispersão.

\section{A Modelagem Analógica}

Os modelos são considerados ferramentas centrais na produção do conhecimento científico e no ensino de Ciências. Isso se deve às relações que estabelecem com a teoria científica, com o mundo (entidades modeladas) e com a aprendizagem de ambos (Morrison e Morgan, 1999; Mozzer, 2013). Nesse sentido, modelos são definidos por Knuuttila (2005) como artefatos que apoiam o pensamento humano e que são materializados a partir de diferentes modos de expressão (verbal, escrito, gestual, concreto, simulação, etc.) para favorecer a sua manipulação em diferentes práticas epistêmicas, como a modelagem. Justi e Gilbert (2002) propuseram uma representação para o processo de modelagem científica, a qual denominaram "Modelo de Modelagem" (Figura 1). O intuito desses autores foi de caracterizar os ciclos recorrentes de criação, expressão, testes e avaliação de modelos envolvidos nesse processo, que estão relacionados entre si e representados por esferas interconectadas na Figura 1. Os três processos cognitivos que permeiam a modelagem também foram representados pelos autores por meio de arestas de cordas que interligam as esferas. São eles: as representações imagéticas e os experimentos mentais, a argumentação e o raciocínio analógico (Gilbert e Justi, 2016).

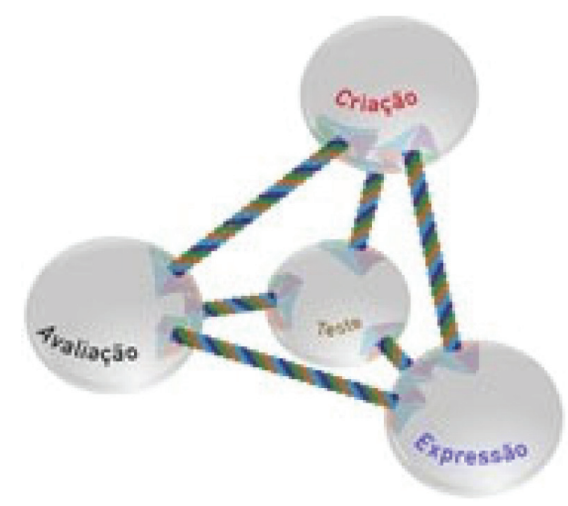

Figura 1: Modelo de Modelagem (Gilbert e Justi, 2016, p. 32).

Para orientar o ensino de Ciências fundamentado na Modelagem, Justi (2006) e Gilbert e Justi (2016) descrevem cada um dos ciclos (ou etapas) mencionados anteriormente. Na etapa de criação, os estudantes devem produzir um modelo inicial, a partir da definição do objetivo do modelo, da experiência com o alvo proporcionada pelo professor ou derivada de seus conhecimentos prévios e da seleção de uma origem para o modelo (como: aspectos da realidade com os quais seja possível estabelecer uma analogia; recursos matemáticos; ou um modelo base para a proposição de outro modelo). A etapa de expressão visa a materialização do modelo por meio de algum modo (concreto, gestual, verbal, matemático, entre outros) que possibilite as discussões entre pares. A etapa de teste compreende a realização de testes mentais ou empíricos do modelo proposto, relacionados ao seu poder explicativo, os quais podem levar a sua revisão ou à proposição de um novo modelo. A etapa de avaliação consiste na análise da abrangência e das limitações do modelo proposto frente ao seu objetivo inicial, e a partir da tentativa de utilizá-lo em outros contextos.

Mozzer e Justi (2018) destacam a importância do raciocínio analógico como processo cognitivo de produção de modelos, pontuando, como Clement (2008), que as analogias podem ser fontes de modelos. Assim, entendidas como comparações de relações de similaridade entre um domínio familiar (análogo) e outro desconhecido ou pouco conhecido (alvo) (Gentner, 1989), as analogias são consideradas neste trabalho como fontes de ideias para a criação e revisão de modelos. Mas consideramos que o contrário também pode ocorrer, ou seja, modelos podem ser fontes de ideias para a criação e revisão de analogias (Mozzer e Justi, 2018). Isso realça a influência mútua que essas ferramentas podem exercer durante a modelagem. A elaboração de modelos pode permitir que aspectos do alvo sejam considerados nas relações de similaridade estabelecidas, assim como o estabelecimento dessas relações pode permitir que novos aspectos do alvo sejam considerados nos modelos propostos.

Com base na proposta de representação e descrição do processo de modelagem científica de Justi e Gilbert, Mozzer e Justi $(2009 ; 2018)$ propuseram adaptações nas etapas descritas anteriormente, de forma que possibilitassem a elaboração, crítica e revisão de modelos e analogias em processos de Modelagem Analógica no ensino de Ciências. Essas etapas podem ser descritas sucintamente como:

- Criação: os estudantes são estimulados a ter ou recordar experiências com o domínio alvo e, paralelamente, selecionar um domínio análogo com o qual seja possível estabelecer uma analogia, que pode funcionar como fonte de um modelo inicial.

- Expressão: os estudantes são solicitados a expressar seus modelos a partir de diferentes modos de representação, dentre os quais, por meio de uma analogia (expressão verbal ou escrita), com explicitação das similaridades e das diferenças entre os domínios comparados.

- Teste: no caso das analogias, os estudantes fazem testes mentais envolvendo as similaridades e as diferenças indicadas. Caso as relações de similaridade não sejam condizentes com o alvo, os estudantes reformulam ou propõem uma nova analogia. $\mathrm{O}$ mesmo ocorre no caso de identificação de possíveis incoerências no modelo proposto.

- Avaliação: quando o modelo e a analogia dos estudantes são bem sucedidos nos testes, é necessária a proposição de novas situações para que eles identifiquem as limitações e a abrangência dos modelos e analogias elaborados e revisados.

Considerando que um dos intuitos de se fundamentar o ensino de Ciências nessas etapas é promover ou ampliar o 
conhecimento dos estudantes em torno de um determinado problema, a modelagem analógica é vista com grande potencial na abordagem de QSC. Nesse processo, a dimensão científica é uma das que pode ser explorada durante as discussões que permeiam as atividades propostas, em conjunção com as dimensões ética, política, social, ambiental, etc.

Neste trabalho, isso se concretizou por meio do desenvolvimento de uma sequência didática centrada em discussões sobre o uso de agroquímicos, embasadas nos modelos e analogias propostos pelos estudantes para explicar o comportamento dessas substâncias.

\section{O Uso de Pesticidas Como Uma QSC}

Autores como Aikenhead (1985) e Conrado (2017) defendem a abordagem de temas que façam sentido no cotidiano dos estudantes, de forma a tornar o ensino mais real e funcional. $\mathrm{O}$ uso de pesticidas² apresenta-se como uma QSC ligada ao cotidiano dos estudantes, a qual possibilita discussões de aspectos ambientais, econômicos, sociais, entre outros.

Os agroquímicos são substâncias de origem natural ou sintética que podem matar diretamente um organismo indesejável ou interferir no seu processo reprodutivo. São comumente utilizados em áreas de agricultura, de pecuária e em domicílios (Peixoto, 2007).

No Brasil, no ano de 2015, houve grande incidência de surtos de doenças como a dengue, zika e febre chikungunya, que são transmitidas pelo mesmo mosquito Aedes aegypti. $\mathrm{O}$ Ministério da Saúde informou em seu Boletim Epidemiológico ${ }^{3}$ que foram registrados 41.264 casos de dengue, 146.914 casos de febre chikungunya e 128.266 casos de zika em todo o país. Campanhas de mobilização para combate à proliferação do mosquito foram promovidas por esse órgão.

O mosquito Aedes aegypti é originário da África e se adapta bem ao ambiente urbano, pois se utiliza, para o desenvolvimento de sua fase larvária, de recipientes diversos com água parada. Essa espécie é antropofílica e tem hábitos diurnos, alimenta-se e deposita seus ovos ao amanhecer (Braga e Valle, 2007).

Os agroquímicos Malathion e Diclorvos, da classe dos organofosforados, são utilizados no controle desse mosquito. A Cipermetrina, da classe dos piretróides, também é um agroquímico utilizado no controle do vetor (Campos e Andrade, 2001). Os organofosforados incluem todos os agroquímicos que contêm em sua composição molecular o átomo de fósforo $(\mathrm{P})$, e possuem toxicidade aguda elevada aos seres humanos e outros mamíferos. A intoxicação por meio desses compostos pode ocorrer via inalação, ingestão ou absorção através da pele, podendo levar a problemas sérios de saúde. Eles se decompõem dentro de dias ou semanas e, com exceção do Diclorvos, possuem baixa volatilidade. A dispersão desses agroquímicos - processo no qual as moléculas de uma substância se dispersam gradualmente por uma região ocupada por moléculas de outra substância, em uma série de etapas aleatórias, sofrendo colisões enquanto se movem (Atkins e Jones, 2012) - ocorre por pulverização, podendo se espalhar pelo vento por uma área de um a dois quilômetros. Eles podem contaminar o meio aquático por meio dos resíduos industriais, da infiltração no solo ou do seu escoamento superficial (Lopes et al., 2011).

Os piretróides são compostos que apresentam ação rápida, eficiência em baixa dose, possuem baixo poder residual no ambiente, são praticamente atóxicos para mamíferos se comparados a vários outros agroquímicos, mas podem exercer efeitos neurotóxicos e cardiotóxicos nos vertebrados, causando paralisia nos insetos (Montanha e Pimpão, 2012).

Como uma alternativa ao uso desses agroquímicos e uma estratégia promissora no combate às larvas do mosquito Aedes aegypti, autores como Furtado et al. (2005) e Garcez et al. (2013) apontam os óleos essenciais, ${ }^{4}$ devido à sua eficiência, além da baixa toxicidade ao ser humano e ao ambiente.

Essa problemática em torno da conscientização sobre as doenças transmitidas pelo mosquito e sobre as formas de combatê-lo são parte da realidade dos estudantes brasileiros e, portanto, pode ser considerada uma QSC ou um problema autêntico nos termos de Aikenhead (1985). Sua abordagem no ensino de Ciências apresenta grande potencial de possibilitar discussões nas dimensões científica, ambiental, social, ética e política, que podem contribuir para a formação de estudantes letrados cientificamente.

\section{Metodologia}

Neste trabalho, trazemos um recorte da análise dos dados da dissertação de mestrado da primeira autora, a qual se encontra em elaboração. Os dados foram coletados durante o desenvolvimento, em sala de aula, da sequência didática (SD) fundamentada na modelagem analógica proposta por Andrade e Mozzer (2017) e descrita nesta seção.

A pesquisa realizada possui um caráter qualitativo, pois tem o intuito de investigar o desenvolvimento de conhecimentos pelos estudantes ao longo da SD. Trata-se, portanto, de uma investigação que foca no processo e em que os dados são predominantemente descritivos (Bogdan e Biklen, 1994).

\section{A Sequência Didática}

De acordo com Zabala (1998), uma SD pode ser entendida como um "conjunto de atividades ordenadas, estruturadas e articuladas para a realização de certos objetivos educacionais, que têm um princípio e um fim conhecidos tanto pelos professores quanto pelos alunos" (p. 18). Embasados nessa visão, Andrade e Mozzer (2017) desenvolveram uma SD que associa o processo de modelagem analógica ao tratamento de uma QSC com os objetivos iniciais de: "favorecer a vivência e compreensão pelos estudantes de aspectos relacionados às práticas científicas presentes na modelagem analógica; favorecer a tomada de decisão frente à questão sociocientífica; favorecer o 
entendimento conceitual de tópicos como: interações químicas, solubilidade e dispersão" (p. 4).

A SD conta com nove atividades, cada uma delas com seus objetivos específicos, mas todos direcionados para auxiliar os estudantes na construção de conhecimentos durante a modelagem para avaliar o uso dos pesticidas:

- Atividade 1: consiste em uma atividade introdutória que tem o objetivo de apresentar e diferenciar as analogias de comparações de mera aparência, por meio da discussão de comparações do cotidiano e de uma comparação comumente estabelecida no ensino de Química.

- Atividade 2: consiste de sete questões, propostas para serem respondidas coletivamente, para que o(a) professor(a) tome conhecimento das ideias e opiniões dos estudantes a respeito da temática pesticida e para familiarizá-los com o caráter dialógico das atividades subsequentes. Por exemplo: O que são pesticidas?; Vocês já utilizaram algum tipo de pesticida em suas casas?; Você já ouviu o termo dedetizar?; $\mathrm{O}$ pesticida pode causar algum dano ao ambiente, pessoas e animais? Quais?; dentre outras.

- Atividade 3: consiste em introduzir informações sobre os pesticidas por meio de um texto explicativo; em específico, apresentar os três pesticidas Malathion, Diclorvos e Cipermetrina, que são comumente utilizados para combate ao mosquito Aedes aegypti (os quais serão o foco do estudo) e discutir os efeitos dessas substâncias à saúde e ao ambiente;

- Atividade 4: consiste em apresentar e discutir uma reportagem sobre a lei que autoriza a pulverização aérea dos pesticidas, e solicitar aos estudantes que criem, expressem, testem e avaliem seus modelos e analogias para explicar a dispersão dos pesticidas na atmosfera, utilizando dados da massa molar e da volatilidade dos pesticidas em estudo;

- Atividade 5: consiste em fornecer e discutir dados sobre o comportamento dos pesticidas em água, que fundamentem os modelos e analogias propostos pelos estudantes para explicar esse comportamento. Os modelos propostos irão subsidiar a análise da possível contaminação da água potável pelos pesticidas;

- Atividade 6: consiste em apresentar os óleos essenciais como uma alternativa para o combate ao mosquito Aedes aegypti. Os estudantes são solicitados a testar seus modelos e analogias anteriores para explicar o comportamento dos óleos essenciais no ar e na água, além de discutir outras maneiras para o combate ao mosquito;

- Atividade 7: consiste em fornecer e discutir novos dados sobre a persistência dos três pesticidas e do óleo essencial, a partir dos quais os estudantes são incentivados a avaliar os modelos e analogias anteriores e a analisar outros riscos de contaminação do ambiente pelos pesticidas;

- Atividade 8: consiste em apresentar, por meio de dois vídeos e uma entrevista escrita, três pontos de vista de especialistas (um médico sanitarista, um químico ambiental e um químico orgânico) sobre os pesticidas e óleos essenciais, com o objetivo de contribuir para a fundamentação dos argumentos dos estudantes na elaboração do parecer na atividade final;

- Atividade 9: consiste na elaboração de um parecer contendo um posicionamento sobre o uso de pesticidas, fundamentado nos modelos e analogias elaborados, nas discussões estabelecidas e nas diferentes fontes de informações a que os estudantes tiveram acesso durante as atividades.

Neste trabalho, analisamos o desenvolvimento da Atividade 4, intitulada "Pesticidas na atmosfera", que teve duração de cinco aulas e o objetivo de trabalhar a dispersão dos pesticidas no ar por meio da proposição de modelos e analogias para representar esse processo. A escolha dessa atividade ocorreu pelo fato de ter sido a primeira em que os estudantes tiveram contato com a elaboração dos modelos e analogias, uma vez que as atividades anteriores foram de caráter introdutório e que as mesmas tinham como objetivo sondar as ideias dos estudantes e promover discussões gerais sobre o tema.

Durante a realização da Atividade 4, os estudantes foram solicitados a explicar o comportamento de três agroquímicos (Malathion, Diclorvos e Cipermetrina) no ar a partir da elaboração de modelos e analogias. Para isso, foi necessário que eles observassem e selecionassem aspectos do domínio alvo que consideraram pertinentes representar no modelo e analogia propostos. Em seguida, os estudantes foram solicitados a expressar seus modelos e analogias verbalmente e por meio de materiais disponibilizados: bolinhas de isopor de diferentes tamanhos, palitos de dente, massinha de modelar, lápis de cor e folhas A4. Nessa etapa de expressão, os estudantes foram solicitados a esclarecer o significado dos códigos de representação adotados em seus modelos e a explicitar as relações de similaridades e as limitações da analogia proposta.

O teste dos modelos e analogias criados foi realizado a partir da análise, pelos estudantes, de seu poder explicativo frente aos dados de massa molar e volatilidade fornecidos na atividade. A etapa de avaliação da modelagem analógica foi contemplada nessa atividade durante as solicitações pelo(a) professor(a) de que os estudantes analisassem as limitações de suas analogias frente aos objetivos iniciais para o quais elas foram elaboradas.

\section{Outros Aspectos Metodológicos}

A pesquisa realizada foi aprovada pelo Comitê de Ética em Pesquisa da Universidade Federal de Ouro Preto. No parecer emitido, o comitê avaliou positivamente aspectos como a relevância da pesquisa; as medidas tomadas para minimizar riscos aos pesquisados durante o seu desenvolvimento; os esclarecimentos prestados aos pesquisados e seus responsáveis quanto à realização da pesquisa, à preservação da identidade dos participantes, à disponibilidade dos resultados finais e à confidencialidade; e as informações fornecidas sobre o arquivamento dos dados. 
Para o desenvolvimento da SD, selecionou-se uma turma de terceiro ano de uma escola pública situada no município de Itabirito, Minas Gerais. Todos os estudantes da turma foram informados de que sua participação na pesquisa seria livre e espontânea, sem remuneração, e que sua identidade seria preservada durante todo processo. Eles receberam os Termos de Consentimento Livre e Esclarecido, os quais foram assinados pelos seus responsáveis, no caso de menores de 18 anos, e por eles mesmos e devolvidos para a pesquisadora.

A seleção da turma foi realizada por se esperar que os estudantes desse nível de ensino possuíssem conhecimentos prévios necessários para se discutir os conceitos químicos trabalhados nas atividades, e pela disposição dos mesmos em participar da pesquisa. Na referida escola, havia uma única turma de terceiro ano no turno noturno, no qual desenvolvemos a nossa pesquisa. Ela contava com 25 estudantes, os quais foram divididos em quatro grupos. ${ }^{5}$ Os estudantes dessa turma ainda não haviam vivenciado atividades de modelagem, e situações argumentativas não eram muito frequentes nas aulas de Química. A SD foi desenvolvida durante 23 aulas de 45 minutos cada. A atividade 4, analisada neste trabalho, foi desenvolvida em cinco aulas sequenciais, da terceira à sétima aulas.

Selecionamos um grupo de 4 estudantes que participou ativamente de todo o processo, e que possuía a maior frequência nas aulas. A participação dos estudantes em todas as atividades da SD foi considerada um critério importante e necessário para a análise do desenvolvimento de seus entendimentos e capacidades durante os processos vivenciados.

Durante o desenvolvimento da SD estiveram presentes três pesquisadoras (havendo sempre duas delas por aula) e a professora, a qual conduziu toda a aplicação da sequência. As pesquisadoras auxiliaram os grupos a todo momento que eram solicitadas, uma vez que, em razão da quantidade de estudantes, era inviável a professora auxiliar os quatro grupos em atividades com as quais eles não tinham familiaridade.

Os dados foram coletados por meio de gravações em áudio e em vídeo. As atividades escritas também foram recolhidas. As gravações em áudio e vídeo foram transcritas, seguindo algumas normas adotadas por Preti (1999; 2009) e Carvalho (2011), a fim de mantermos um padrão de códigos e facilitar o entendimento dos dados. Por exemplo, a numeração sequencial dos turnos de fala ao longo da transcrição e a utilização dos dois parênteses (( )) para a inserção de comentários do pesquisador sobre gestos e ações dos sujeitos.

$\mathrm{Na}$ descrição e análise dos dados utilizamos nomes fictícios para nos referir aos estudantes. Com relação à professora e às pesquisadoras, usamos os termos "Professora", "Pesquisadora 1", "Pesquisadora 2" e "Pesquisadora 3".

O conjunto de dados foi analisado com o objetivo de identificar evidências que apontassem o desenvolvimento do entendimento dos estudantes sobre o conceito de dispersão. Dessa forma, selecionamos trechos das transcrições dos diálogos estabelecidos entre os estudantes, a professora e as pesquisadoras ao longo das etapas da modelagem analógica, e imagens dos modelos concretos elaborados, que nos possibilitassem discutir essas evidências do entendimento conceitual dos estudantes.

\section{Resultados e Discussão}

$\mathrm{Na}$ primeira aula da atividade 4 , a professora leu com a turma uma reportagem intitulada "Nova lei contra o Aedes que prevê pulverização aérea de inseticida gera protestos". ${ }^{6}$ Após a leitura, ela propôs uma situação fictícia: os estudantes fariam parte de uma comissão técnico-científica que pesquisaria o comportamento dos pesticidas no ambiente, com o objetivo de emitir um parecer por meio do qual se posicionariam contra ou a favor do uso dessas substâncias para combater o mosquito Aedes aegypti.

Após a explicação da professora sobre o objetivo da atividade, a pesquisadora 3 foi até o grupo investigado para esclarecimento das dúvidas dos estudantes sobre o que seria feito na segunda parte da atividade, intitulada "Como os pesticidas se comportam na atmosfera?". Naquele momento, ela questionou os estudantes sobre como os pesticidas se comportam quando são lançados no ar, e eles explicaram que suas partículas caem e se espalham na plantação. Na tentativa de que os estudantes voltassem suas explicações para o nível submicroscópico, a pesquisadora auxiliou-os na interpretação das fórmulas moleculares dos pesticidas Malathion, Diclorvos e Cipermetrina, que foram disponibilizadas na atividade, e solicitou que eles representassem o comportamento das partículas desses compostos ao entrarem em contato com o ar e o explicassem na aula seguinte.

$\mathrm{Na}$ segunda aula de desenvolvimento da atividade 4 , os estudantes inicialmente demonstraram dificuldade em como deveriam expor suas ideias. Após uma explicação mais detalhada sobre o que seria o nível submicroscópico, os estudantes começaram a propor o modelo expresso no trecho transcrito a seguir:

81. Wagner: A gente tem que juntar muitas bolinhas. Esse pode ser o pesticida ((aponta para a bolinha de isopor de tamanho maior)). A gente faz e coloca no palitinho. Um palitinho coloca aqui ((mostra a inserção do palito entre a bolinha de isopor menor e a maior)) e coloca outro palitinho aí ((indica a outra bolinha de isopor maior)). Coloca mais e separa... Tipo... Coloca o ar e aí a gente pega mais um palito e coloca o pesticida. Entendeu?

82. Eliane: Então começa aí.

83. Wagner: Entendeu? No final coloca esse ((mostra a bolinha de isopor menor)).

84. Eliane: Não. No final já tem ((se refere à bolinha de isopor menor representando o ar no modelo da Figura 2)).

85. Wagner: Vai ligando eles... Essa daqui oh ((aponta para a bolinha menor 'ligada' à bolinha maior))... A gente coloca um monte de palitinhos para terminar...

86. André: Tem esse daqui ((aponta para uma bolinha de isopor colorida de laranja, Figura 2)). 
87. Wagner: Pode ser até esses pintados ((se referindo as bolinhas que foram pontilhadas pelo grupo))... Me dá aí André. Só as maiores... Deixa eu escrever aqui como que escreve ((escreve pesticida)).

88. Mariana: Não estou entendendo isso ((se referindo a bolinha de isopor menor do modelo da Figura 2)).

89. Eliane: Aqui, Mariana, é só em cima ((aponta para a bolinha de isopor menor do modelo, se referindo à partícula do ar)).

93. Pesquisadora 1: Aqui ((aponta para as bolinhas de isopor maiores da Figura 1)) você representou o quê?

94. Wagner: Pesticidas. E aí eles vão se espalhando com o ar. 95. Eliane: Aí nossa plantação está aqui ((mostra uma representação de grama, confeccionada com massinha de modelar, que pode ser visualizada na Figura 3)) ela tem bichinhos para matar eles.

96. Pesquisadora 1: Entendi. Agora só uma pergunta, aqui ((se refere às bolinhas maiores)) você está representando o pestici$d a, n e ́(($ se refere às bolinhas maiores))? As partículas deles, né? 97. Wagner: É, várias moléculas de pesticidas.

98. Pesquisadora 1: Mas aí ((aponta para a bolinha de isopor menor)), você representou só uma partícula de ar?

99. André: É. Tem que ter mais.

100. Wagner: Tem que ter mais.

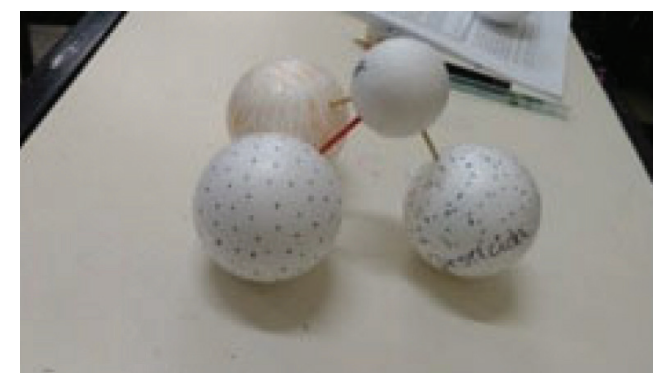

Figura 2: Representação da dispersão do pesticida no ar.

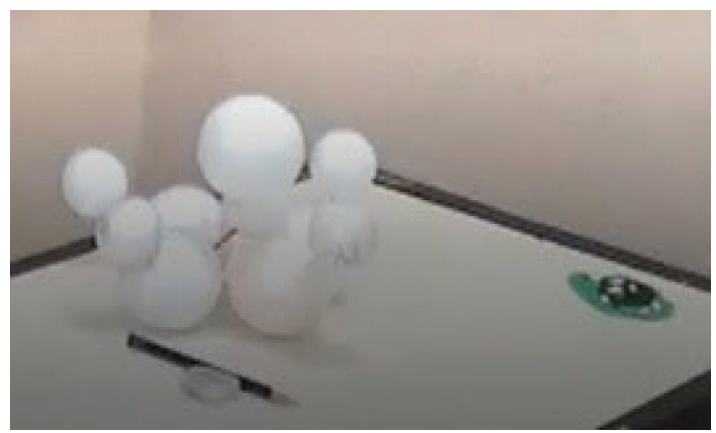

Figura 3: Modelo reformulado da dispersão do pesticida no ar (detalhe da grama à direita da figura).

Como evidencia esse trecho, os estudantes do grupo iniciaram uma discussão sobre como eles iriam propor a representação, trabalhando de forma colaborativa na tentativa de criar e expressar um modelo para representar a dispersão das partículas do pesticida no ar. Percebemos, por meio do modelo expresso pelo grupo (vide Figura 2) e da discussão com a Pesquisadora 1 , que eles imaginavam ser suficiente representar $\mathrm{o}$ ar por meio de uma única bolinha de isopor (turnos 81 ao 84), indicando que os estudantes entendiam que o mesmo seria constituído por uma única substância. Trabalhos como o de Melo e Silva (2017) reportam a dificuldade dos estudantes de formar um conceito científico de ar, os quais tendem a pensá-lo como constituído apenas de oxigênio e não de uma mistura de gases. Outra ideia evidenciada foi a de que as partículas dos constituintes dos pesticidas e do ar estariam ligadas quimicamente umas às outras (turnos 81 ao 85). Essa ideia dos estudantes também foi identificada por autores como Fernandez e Marcondes (2006), Kind (2004), Quadros et al. (2017) e Queiroz (2009), que realçam que uma de suas possíveis origens pode ser a ausência de esclarecimentos no ensino do tema sobre o significado do uso de palitos, bolinhas, esferas na representação das ligações químicas.

Ao serem questionados pela pesquisadora sobre os códigos de representação utilizados, os estudantes afirmaram que as bolinhas de isopor maiores representavam os pesticidas e que eles estariam se espalhando no ar (turnos 93 ao 95). Dando continuidade à discussão ela também os questionou sobre a quantidade de bolinhas que eles usaram no modelo da Figura 2 (turnos 96 ao 100). A partir desses questionamentos, os estudantes passaram pelo primeiro momento de teste do modelo, reconhecendo a incoerência da representação e propondo a sua reformulação, como indica o trecho transcrito a seguir.

111. Eliane: Deixa o modelo assim é só completar.

112. Wagner: André me empresta essa daí ((se referindo à bolinha de isopor menor)) para colocar aqui.

113. Mariana: Coloca mais dessa bolinha aqui ((se referindo à bolinha de isopor maior)).

114. Wagner: E onde eu vou colocar ela? ((se referindo às bolinhas de isopor maior)).

115. Eliane: Embaixo... Embaixo de tudo ((aponta para o modelo da Figura 1)).

116. Wagner: As bolinhas vão cair, não vai parar ((se refere à sustentação da estrutura)).

117. André: Coloca mais palitos para segurar.

118. Professora: $O$ que vocês estão fazendo aí? O que vocês estão representando?

119. Wagner: É porque a gente fez aqui em cima ((aponta para as bolinhas de isopor maiores)) o pesticida e ele entra em contato com o ar e vai se espalhar. Aqui a gente colocou mais partículas das substâncias do ar ((se refere às bolinhas de isopor menores que foram adicionadas ao modelo da Figura 2)).

120. Professora: Entendi.

121. Eliane: E isso daqui é a grama e os bichinhos da plantação ((se refere à representação em massa de modelar à direita na Figura 2)). Então vai jogar o pesticida aqui nos bichinhos. 122. Professora: Então, olha só quando a gente está representando a grama e os bichinhos tudo isso daí é o macroscópico. É o que a gente está vendo, certo? E aí a gente está querendo saber como que as partículas vão se espalhar, pensando no nível submicroscópico. 
É possível perceber que Wagner sugeriu inserir a bolinha de isopor menor (associada à partícula de ar) no modelo, enquanto Mariana sugeriu inserir a bolinha de isopor maior (associada à partícula de pesticida) (turnos 112 ao 114). A partir da sugestão de André de utilizar mais palitos de dente para sustentar o modelo (turno 117), os estudantes optaram por aumentar a quantidade de bolinhas de isopor de ambos os tamanhos para representar as partículas de ar e de pesticidas (Figura 3).

Após a reformulação do modelo, a professora solicitou ao grupo que explicasse sua representação. A explicação fornecida por Wagner (turnos 118 ao 120) nos indica que o grupo compreendeu que o ar é constituído por partículas de diferentes substâncias. A partir da complementação da explicação pela estudante Eliane sobre a representação da grama, a professora buscou novamente diferenciar os níveis macroscópico e submicroscópico (turnos 121 e 122), com o intuito de que os estudantes compreendessem a incoerência de se conjugar representações nos níveis macro e submicroscópico em um mesmo modelo.

Estudos como os de Rappoport e Ashkenazi (2008) e Al-Balushi (2013) retratam a dificuldade dos estudantes em transitar de maneira adequada entre os diferentes níveis de representação, de pensar espontaneamente em explicações no nível submicroscópico e de compreender o papel de cada nível e de suas relações. Isso justifica as ações recursivas da professora e das pesquisadoras durante as atividades, no sentido de auxiliar os estudantes neste tipo de entendimento.

$\mathrm{Na}$ terceira aula, a pesquisadora retomou com o grupo a discussão sobre o modelo reformulado (Figura 3), a fim de auxiliar os estudantes a concluírem o modelo e a refletirem sobre algumas das ideias expressas por meio do mesmo.

152. Pesquisadora 1: Como vocês representaram aqui? ((referindo ao modelo da Figura 3)).

153. André: Os pesticidas e o ar.

154. Pesquisadora 1: Entendi. Aí, qual bolinha vocês estão representando o ar? E qual está representando o pesticida?

155. André: As menores são o ar.

156. Wagner: As maiores são os pesticidas.

157. Pesquisadora 1: E como essas partículas vão estar no ar? De que forma?

158. André: Espalhadas.

159. Pesquisadora 1: Esse modelo de vocês representa que elas estão espalhadas?

160. André: Acho que está.

161. Wagner: Tá. ((aponta para o modelo da Figura 3)).

162. Pesquisadora 1: E o que significa esse palito aqui... que está entre as partículas do ar e do pesticida aqui ((aponta para um dos palitos da representação da Figura 3))?

163. Eliane: É...

164. André: Sei lá.

165. Pesquisadora 1: Se vocês jogarem o pesticida aqui ((se referindo à sala de aula)) ele vai atingir a quadra?

166. Eliane: Vai, vai se espalhando assim ((movimento circular com as mãos)) através do ar e vai...
167. Pesquisadora 1: Se espalhando como? De que forma? $O$ modo que vocês representaram aqui ((se referindo ao modelo da Figura 3)) parece que está todo mundo junto. Esses palitos estão dando a ideia de quê?

168. André: De um estar ligado no outro.

169. Pesquisadora 1: É isso que vocês queriam passar? Que a partícula do pesticida se liga na partícula do ar?

170. André: Sim.

171. Pesquisadora 1: Aqui ((aponta para o modelo da Figura 3)) vai formar uma nova substância, ou o pesticida vai continuar sendo pesticida e interagir com o ar? Aí está falando que vai formar outra coisa?

172. Eliane: Não.

173. Wagner: Não.

174. Eliane: Mas como vai separar? ((se refere ao modelo da Figura 3)). Eu não sei.

175. Pesquisadora 1: Eliane você me falou assim, os pesticidas estão espalhados no ar ((movimento circular com as mãos)). Então, como você poderia representar ele aí?

176. André: Tirando os palitos que estão entre as bolinhas. 177. Wagner: Assim não estão ligados, só interagindo. ((aponta para o modelo da Figura 4)).

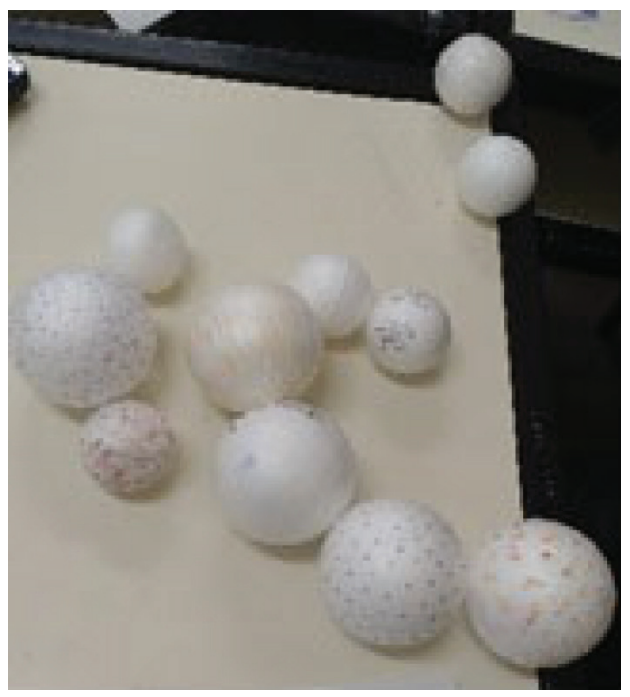

Figura 4: Modelo reformulado dos pesticidas no ar.

No trecho acima, podemos notar uma nova explicitação do grupo em relação aos códigos usados no modelo reformulado da Figura 3 (turnos 152 ao 158). Além disso, a fim de entender o significado do termo "espalhadas", usado pelos estudantes em diferentes momentos de discussão, e de contrapor tal significado com a utilização dos palitos na representação da Figura 3 , a pesquisadora questionou o grupo, dando início ao segundo momento de teste do modelo.

Para auxiliar os estudantes nesta etapa de teste, a pesquisadora buscou diferenciar a formação de novas substâncias, que caracteriza uma reação química, do estabelecimento de interações entre as partículas constituintes das substâncias (turnos 171 ao 173). Mortimer e Miranda (1995) explicam 
que a dificuldade dos estudantes na compreensão das reações químicas pode estar associada ao fato de que eles nem sempre reconhecem as entidades que se transformam e as que permanecem constantes. Tal incompreensão também pode refletir e ser influenciada pela dificuldade de diferenciar as interações interatômicas das intermoleculares (Peterson e Treagust, 1989; Nakhleh, 1992).

A ação da pesquisadora de discutir sobre as diferenças entre reação e interação parece ter levado os estudantes ao reconhecimento de uma nova incoerência, e da necessidade de reformular o modelo proposto, devido à compreensão de que não haveria uma reação química entre os componentes do ar e do pesticida durante a dispersão, mas interações entre suas partículas. Essa compreensão foi expressa nas falas de André (turno 176) e de Wagner (turno 177), que propuseram a retirada dos palitos na reformulação do modelo para representar as interações estabelecidas entre os pesticidas e o ar.

Dando sequência à atividade, a pesquisadora solicitou que os estudantes propusessem uma analogia para explicar o comportamento dos pesticidas que eles haviam representado, e que identificassem as relações de similaridade entre os domínios comparados e as limitações da comparação. $\mathrm{O}$ trecho a seguir ilustra aspectos importantes das discussões que ocorreram em consequência dessas solicitações.

215. Eliane: Poderia ser aquele negócio de banheiro, porque espalha e dá um cheiro.

216. Wagner: Então fala com ela ((se referindo à pesquisadora)). 217. Eliane: Então, como chama aquele negócio de jogar no banheiro e dá cheiro. Aquilo que faz ((balança a mão e faz som com a boca de xiiiiiii))... É bom ar que fala?

218. Wagner: Isso.

219. André: $E$.

220. Wagner: Pode ser quando eи vou usar um perfume assim... que eu jogo ((faz o movimento no corpo)).

221. Eliane: Mas isso vai ser só pra mim, no meu corpo. Tipo o bom ar vai se espalhar no ar todo. Tipo, se você estiver no quarto vai sentir.

((A Pesquisadora 1 dirige-se para o grupo para que os estudantes expressem sua proposição)).

222. Pesquisadora 1: O que vocês pensaram?

223. Eliane: É porque os pesticidas entram em contato com o ar atingindo a plantação, né? Aí, sabe aquele negócio que você joga no cômodo, para dar cheiro?

224. Pesquisadora 1: $O$ bom ar?

225. Eliane: Isso! Aí, tipo... se você jogar ele no quarto, ele vai se espalhar no quarto todo e vai dar o cheiro. Você vai sentir aquele cheiro, porque ele vai se espalhar através do ar.

226. Pesquisadora 1: Então, qual a relação de semelhança que a gente pode fazer com o bom ar e com os pesticidas no ar? 227. Eliane: Tipo... vai ser a mesma coisa. Tudo que acontecer com esse daí ((se referindo ao modelo da Figura 4)), vai acontecer no bom ar. O pesticida vai estar espalhando suas partículas através do ar, ele vai se espalhando e atingindo as plantações. A mesma coisa acontece com o bom ar. Você vai jogar no ar e vai se espalhando. Tipo... qualquer lugar de um cômodo você vai sentir o cheiro. Normal, igual acontece com esse daí.

((A Pesquisadora 2 se junta à Pesquisadora 1)).

228. Pesquisadora 2: As partículas aqui do ar e dos pesticidas elas estão paradinhas assim? ((aponta para o modelo da Figura 4)).

229. Eliane: Não.

230. Pesquisadora 2: Como elas estão?

231. Eliane: Em movimento.

232. Wagner: Movimento.

233. Pesquisadora 2: E no caso do bom ar?

234. Eliane: Tipo... vai estar em movimento também, circulando. 235. Pesquisadora 1: Por quê?

236. Eliane: Porque tipo, ah...

237. Wagner: Em qualquer lugar do cômodo vai ((faz movimento circular com o braço)).

238. Eliane: Porque se você colocar no quarto... você espirrasse no quarto, vai ficar circulando e você vai sentir o cheiro no outro cômodo. Ele vai ficar circulando, em movimento.

239. Pesquisadora 2: Se elas estão se movimentando, elas podem se chocar umas nas outras? O pesticida no ar, e o bom ar no ar?

240. Wagner: Pode. Elas estão em movimento...

241. André: Pode, elas vão se chocar.

Dando início às etapas de criação e expressão da analogia, Eliane sugeriu aos seus colegas comparar o comportamento dos pesticidas no ar com o de um odorizador de ambiente. $\mathrm{O}$ perfume foi apresentado por Wagner como outra possibilidade de análogo. Essa ideia foi refutada por Eliane com a justificativa de que o alcance das partículas do $\operatorname{Bom} \operatorname{Ar}{ }^{\circledR}$ seria maior do que as do perfume (turnos 215 ao 225).

Naquela situação, o argumento de Eliane parece ter sido aceito pelo grupo, visto que deram continuidade à discussão do análogo proposto pela mesma, seja pelo fato de terem considerado plausível a justificativa de maior alcance do odorizador, ou porque se configurou em um "argumento de autoridade", cuja aceitação está mais ligada ao status daquele que o produziu do que à plausibilidade das ideias que o embasam (Jiménez-Aleixandre, 2010). No caso de Eliane, esse possível status parece evidenciado em diferentes momentos em que seus comandos e sugestões foram acatados pelo grupo, como: aquele em que ela ordena que Wagner inicie o modelo da Figura 2 (turno 82); quando ela auxilia Mariana na construção do modelo (turno 89); quando ela sugere não modificar o modelo da Figura 2 e apenas completá-lo após o primeiro teste (turno 111), opinando sobre onde deveriam ser colocadas as bolinhas de isopor (turno 115).

Ao retornar ao grupo a pesquisadora 1 solicitou aos estudantes que expressassem a analogia proposta. Eliane se prontificou, explicitando como única similaridade o espalhamento 
do odorizador e do pesticida no ar (turnos 222 ao 227). Com a intenção de auxiliar os estudantes na identificação de outras relações de similaridade possíveis de serem estabelecidas a partir da analogia proposta, a pesquisadora 2 se juntou à pesquisadora 1 para promover tal discussão (turnos 228 ao 241). Ela questionou novamente o grupo sobre o comportamento das partículas a partir do modelo proposto. Isso possibilitou a identificação de outras duas relações de similaridade pelos estudantes, referentes aos aspectos discutidos anteriormente: a movimentação e os choques entre as partículas no alvo e no análogo (vide Quadro 1).

Dessa forma, notamos que os questionamentos realizados aqui e em outros momentos pelas pesquisadoras e pela professora, durante as explicações dos modelos e analogias pelos estudantes, contribuíram de forma significativa para que eles pudessem refletir, compreender e construir suas ideias. Isso é consonante com os resultados de trabalhos como de Andrade et al. (2017) e Andrade e Mozzer (2016), que realçam a importância desses questionamentos para orientar a condução de atividades de modelagem analógica e minimizar as dificuldades encontradas pelos estudantes durante as etapas do processo.

Apesar de terem sido capazes de estabelecer uma analogia no sentido definido por Gentner (1989), os estudantes não foram capazes de identificar relações de ordem superior, ou seja, relações de relações nessa comparação. No caso da analogia proposta, eles teriam evidenciado uma compreensão ainda mais elaborada do domínio alvo se tivessem sido capazes de identificar a relação causal entre o espalhamento das partículas e a movimentação e os choques das mesmas, visto que essa relação causal é estabelecida a partir da inter-relação das outras relações de similaridade.

Dando continuidade à discussão da analogia, a pesquisadora 1 solicitou aos estudantes que explicitassem as limitações que haviam identificado na comparação proposta, o que os levou a passar pela etapa de avaliação da analogia. As limitações foram sintetizadas no Quadro 1, e o trecho do diálogo que ilustra sua discussão encontra-se transcrito a seguir.

291. Pesquisadora 1: Lembra quando eu falei ((mostra na folha de atividade)) para vocês falarem da semelhança e da limitação? Então em qual limitação vocês pensaram?

292. Eliane: A diferença pode ser que esse daqui ((se referindo ao odorizador)) vai ser para dar cheiro e esse daí ((se referindo ao pesticida)), para matar... pode ser tóxico. E esse de cá ((se referindo novamente ao odorizador)) não. Porque assim... se esse bom ar fosse para matar, você não poderia usar ele dentro de casa. Então pode ser essa diferença.

293. Wagner: Matar as pragas e esse ((aponta para o odorizador)) para perfumar o ambiente.

294. Pesquisadora 1: Entendi. Isso pode ser uma limitação. Vocês conseguem pensar em outra?

295. Pesquisadora 2: E quando a gente pensa assim, tudo que é jogado em ar livre vai se espalhar na mesma velocidade que o que não está em ar livre?

296. Wagner: Não.

297. Eliane: Acho que não, porque o vento que está lá fora é mais forte.

298. Wagner: Vai se espalhar mais rapidamente.

299. Eliane: $O$ ar é mais forte e vai se espalhar mais rápido em lugar aberto do que no lugar fechado.

Como uma das limitações da comparação elaborada, o grupo apontou a diferença de toxicidade dos pesticidas em relação ao odorizador (turno 291 ao 293). Essa identificação parece ter sido baseada nas experiências vivenciais dos estudantes com a utilização de odorizadores e inseticidas, uma vez que ela não foi associada às diferentes composições de pesticidas e odorizadores. Outra limitação identificada pelos estudantes diz respeito às diferentes velocidades de difusão do odorizador em relação aos pesticidas, em decorrência da diferença de movimentação do ar em ambiente externo e interno (turnos 295 ao 299).

$\mathrm{Na}$ quarta aula, a professora apresentou para toda a turma informações sobre a massa molar e a volatilidade dos pesticidas, além de relembrar conceitos já discutidos. Os grupos foram solicitados a levar em consideração as novas informações para tentar explicar o comportamento de cada pesticida, utilizando,

Quadro 1: Relações de similaridade estabelecidas pelos estudantes entre a dispersão das partículas de um odorizador e as partículas no ar

\begin{tabular}{|c|c|c|}
\hline $\begin{array}{l}\text { Análogo } \\
\text { (Comportamento do Bom } \mathrm{Ar}^{\circledR} \text { no ar) }\end{array}$ & Correspondência & $\begin{array}{c}\text { Alvo } \\
\text { (Comportamento do Pesticida no ar) }\end{array}$ \\
\hline Movimentação das partículas & & Movimentação das partículas \\
\hline $\begin{array}{l}\text { Choque entre as partículas do Bom } \mathrm{Ar}^{\circledR} \text { com as partículas } \\
\qquad \text { do ar }\end{array}$ & & $\begin{array}{l}\text { Choque entre as partículas dos pesticidas com as } \\
\text { partículas do ar }\end{array}$ \\
\hline $\begin{array}{l}\text { Espalhamento das partículas do } \mathrm{Bom}^{\mathrm{A} r^{\circledR}} \text { entre as } \\
\text { partículas de ar }\end{array}$ & & $\begin{array}{l}\text { Espalhamento das partículas do pesticida entre as } \\
\text { partículas de ar }\end{array}$ \\
\hline \multicolumn{3}{|c|}{ Limitações } \\
\hline \multicolumn{3}{|c|}{$\begin{array}{l}\text { - Diferença de toxicidade dos pesticidas em relação ao odorizador; } \\
\text { - Diferentes velocidades de difusão do odorizador em relação aos pesticidas, em decorrência da diferença de movimentação do ar em ambiente } \\
\text { externo e interno. }\end{array}$} \\
\hline
\end{tabular}


para isso, os modelos e analogias propostos anteriormente (terceiro momento de teste).

347. Pesquisadora 1: Quais são as possíveis diferenças que existem entre esses três pesticidas?

348. André: A massa molar.

349. Pesquisadora 1: O Malathion então tem a massa molar de 330. Ela é o quê em relação a do Diclorvos?

350. Wagner: Maior.

351. Pesquisadora 1: E a da Cipermetrina?

352. André: Maior.

353. Wagner: Maior ainda.

354. Pesquisadora 1: E o que a massa molar tem a ver com a volatilidade aqui, de acordo com a tabela. Qual é a relação que vocês podem observar aí?

355. Wagner: Eu acho que quanto menor a massa molar, maior a volatilidade.

356. André: O Diclorvos, ele vai espalhar, andar mais rápido.

357. Pesquisadora 1: E porque ele vai se espalhar mais rápido?

358. Wagner: Porque ele tem menos massa.

359. Pesquisadora 1: E o Malathion?

360. Wagner: Tem massa molar maior e vai demorar mais a se espalhar.

361. Pesquisadora 1: $O$ que vai acontecer com os pesticidas de maior massa?

362. Wagner: Que uns vão chegar primeiro.

363. Pesquisadora 1: O que mudou agora?

364. Eliane: A velocidade.

365. Pesquisadora 1: Então este modelo aqui explica o comportamento dos três pesticidas?

366. Wagner: Não. Esse modelo era o geral ((aponta para o modelo da Figura 4)) a gente não deu nome para nenhum, foi geral. Aqui por exemplo a gente tem que dar nome para cada pesticida.

((Estudantes discutem entre si)).

367. André: Mas tipo, eu estou pensando assim, os maiores vão ocupar mais espaços que os menores. Então será que eles vão ficar mais parados? Se bem que é a massa. Então, como ele vai ficar?

368. Wagner: Aqui, André, a gente tem esse que é o ar ((aponta para a bolinha menor)). Para a gente reformular nosso modelo, tipo esses que tem mais massa ((aponta para as bolinhas)) são os maiores, aí o pequeno a gente coloca uma bolinha menor. 369. André: As menores vão ser as pequenininhas, e as pequenininhas passam mais fácil pelas maiores. E as maiores podem ser essas daqui oh ((aponta para as bolinhas de isopor maior)) pela massa do Diclorvos.

370. Wagner: Se a gente desse o nome, por exemplo, esse daqui tem quantidade de massa menor então chegaria...

371. André: Passaria mais fácil.

372. Wagner: Chegaria mais rápido. Mas eu acho que se a gente desse nome...

373. André: Mas a massa vai interferir na velocidade... mas agora como vai fazer?
374. Wagner: Mas a diferença logicamente vai ser de boa. $O$ que tiver a massa molar menor, vai se espalhar mais rápido, terá maior velocidade. O que tiver massa molar maior demora mais, a velocidade é menor.

No terceiro momento de teste, na tentativa de usar o modelo da Figura 4 para explicar a relação da massa com a velocidade de espalhamento dos pesticidas no ar (turnos 366 ao 368), os estudantes perceberam que haviam representado todos os tipos de pesticidas com bolas de isopor de um mesmo tamanho, diferenciando-as apenas pelas cores dos pontinhos de caneta que fizeram nelas. Diante disso, eles reformularam o modelo, expressando-o por meio da linguagem verbal, na qual utilizaram expressões como: "passam mais fácil pelas maiores" (turno 369); "chegaria mais rápido" (turno 372); e "o que tiver a massa molar menor vai espalhar mais rápido" (turno 374). Essas expressões nos fornecem indícios de uma compreensão mais elaborada da influência da massa das partículas na sua velocidade de dispersão (partículas de pesticida de maior massa se espalhariam no ar com menor velocidade do que aquelas de menor massa).

Jiménez-Aleixandre (2010) sinaliza, em seu trabalho, a importância do raciocínio argumentativo para o ensino de Ciências, uma vez que os estudantes são levados a construir explicações e aprender conceitos, além de desenvolver capacidades distintas de explicação. Isso pode ser observado, por exemplo, nesse terceiro momento de teste do modelo realizado pelos estudantes: diante das novas informações apresentadas, os estudantes modificaram seu modelo explicativo apoiados no desenvolvimento de um argumento fundamentado na relação entre a massa e a volatilidade dos pesticidas.

Como se deu em relação ao modelo, os estudantes também foram questionados sobre a adequação da analogia proposta para explicar a relação entre a massa molar e a velocidade das partículas. $\mathrm{O}$ grupo percebeu a necessidade de reformular sua analogia, uma vez que as similaridades estabelecidas não contemplavam aquela explicação, mas apresentaram dificuldade em fazê-lo. Eles foram, então, auxiliados pela professora.

Na quinta aula, o grupo apresentou a analogia reformulada durante o momento de socialização das ideias com a turma, como ilustra o trecho transcrito a seguir.

834. Pesquisadora 1: Qual foi a analogia que vocês fizeram? Com o quê vocês compararam?

835. André: Com o bom ar.

836. Professora: E aí como vocês estabeleceram a comparação com o bom ar?

837. Mariana: Nós identificamos a diferença das massas, que quando a massa molar é maior a partícula tem mais dificuldade de passar do estado líquido para o estado gasoso.

838. Professora: Vamos só retomar. Qual é o seu análogo?

839. Mariana: Estamos comparando o pesticida com o bom ar. As diferenças das massas são que quando a massa é maior, ele tem mais dificuldade de passar do estado líquido para o estado 
gasoso. O pesticida com massa menor irá ter mais facilidade de se espalhar no ar do que um com a massa maior. As moléculas no estado líquido estão um pouco atraídas umas nas outras e no gasoso se encontra com mais movimento. Nossa limitação é que o pesticida fica em um espaço aberto com vento e espalha mais rápido, e o bom ar é só em lugar fechado.

840. Professora: Tá bom então. Essa diferença é a mesma que as outras analogias apresentadas pelos outros grupos do alcance. Se eu comparar apenas um bom ar ele vai ter a mesma composição, então teremos alguma diferença?

841. André: Não.

842. Mariana: Por isso a gente comparou o bom ar com o glade. 843. Wagner: Dois tipos diferentes.

844. Mariana: Dois tipos diferentes de marca.

845. Professora: Entendi. Então o que vai acontecer com esses dois tipos diferentes?

846. Wagner: Vai ter composição diferente o que levará a ter massa molar diferente.

847. Mariana: E volatilidade diferente.

848. Professora: Isso mesmo. A mesma ideia do perfume apresentada pelo outro grupo: dois tipos de perfume diferentes e com isso vão ter comportamentos diferentes. Assim acontece com o bom ar. Só que aí a dispersão é uma reação química? 849. Wagner: Não.

850. André: Não.

851. Mariana: Não.

852. Mariana: Ele vai apenas passar do estado líquido para o estado gasoso e espalhar.

853. Wagner: Ele vai continuar sendo bom ar.

Ao serem questionados pela professora, os estudantes André e Mariana explicitaram novamente as relações de similaridade da analogia reformulada (turnos 835 ao 839). O grupo apresentou como análogo ao comportamento dos pesticidas (alvo) dois tipos de odorizadores de ar $\left(\mathrm{Bom} \operatorname{Ar}{ }^{\circledR}\right.$ e Glade $\left.{ }^{\circledR}\right)$ e forneceu indícios, durante a discussão de socialização das ideias, de uma compreensão mais elaborada do alvo por ter sido capaz de estabelecer as seguintes relações entre os domínios (vide Quadro 2): compostos diferentes são constituídos de partículas com massas molares diferentes; a volatilidade de um composto depende da massa de suas partículas; partículas de maior massa molar têm maior dificuldade para passar da fase líquida para a gasosa.

Nesse momento, é possível notar a influência mútua discutida por Mozzer e Justi (2018) entre os modelos e as analogias no processo de modelagem analógica. Nesse caso, como discutido, os estudantes buscaram reformular a comparação para contemplar a relação entre a massa e a volatilidade dos compostos, que passou a fundamentar o seu modelo explicativo. Isso pode ser observado também em outros momentos das atividades, como nos turnos de fala 228 ao 241, quando os estudantes foram questionados sobre o modelo da Figura 4 e conseguiram, a partir dele, estabelecer outras duas relações de similaridade entre o análogo e o alvo, referentes à movimentação e aos choques entre as partículas.

Essa influência pode ser notada ainda em momentos como aquele em que os estudantes expressaram a limitação da diferença de velocidade de espalhamento das partículas na primeira analogia (turnos de fala 295 ao 299). Esse aspecto parece ter inspirado a discussão posterior sobre a influência das massas molares nessa diferença de velocidades de espalhamento das partículas dos pesticidas, durante a reformulação do modelo explicativo (turnos de fala 363 ao 374). Assim, torna-se notável o papel de modelos e analogias como ferramentas de pensamento, visto que os mesmos foram manipulados em diferentes momentos das atividades (como este) para a criação e desenvolvimento de ideias pelos estudantes.

Como limitação dessa comparação o grupo voltou a identificar os diferentes alcances das substâncias, o que é ocasionado pela diferença de movimentação do ar em ambientes fechados e abertos (turno 839), sem mencionar a diferença de toxicidade como haviam feito num primeiro momento (vide Quadro 1). Isso pode indicar que, ao avaliarem a comparação, os estudantes perceberam que a limitação referente à diferença de comportamento das partículas dos análogos comparados seria mais adequada face ao objetivo inicialmente estabelecido pela professora para a criação da analogia: explicar o comportamento dos pesticidas e do ar no nível submicroscópico.

Quadro 2: Analogia estabelecida pelos estudantes entre a dispersão das partículas de odorizadores e pesticidas no ar e sua limitação

\begin{tabular}{|c|c|}
\hline $\begin{array}{c}\text { Análogo } \\
\text { (Comportamento do Bom Ar }{ }^{\circledR} \text { e do Glade }{ }^{\circledR} \text { no ar) }\end{array}$ & Correspondência \\
\hline $\begin{array}{c}\text { Odorizadores diferentes são compostos por partículas de } \\
\text { massas molares diferentes }\end{array}$ & $\begin{array}{c}\text { Pesticidas diferentes são compostos por partículas de } \\
\text { massas molares diferentes }\end{array}$ \\
\hline $\begin{array}{c}\text { A diferença de massa das partículas dos diferentes } \\
\text { odorizadores determina a diferença de volatilidades } \\
\text { destes }\end{array}$ & $\begin{array}{c}\text { A diferença de massa das partículas dos diferentes } \\
\text { pesticidas determina a diferença de volatilidades destes }\end{array}$ \\
\hline $\begin{array}{c}\text { Partículas de maior massa molar têm maior dificuldade de } \\
\text { passar da fase líquida para a gasosa }\end{array}$ & $\begin{array}{c}\text { Partículas de maior massa molar têm maior dificuldade de } \\
\text { passar da fase líquida para a gasosa }\end{array}$ \\
\hline \multicolumn{2}{|c|}{} \\
\hline \multicolumn{2}{|c|}{ L alcanimitação } \\
\hline
\end{tabular}


Além desses aspectos, o episódio nos fornece um novo indício de que os estudantes compreenderam que a dispersão não é um fenômeno químico. Isto pode ser observado a partir das respostas de Wagner e Mariana ao questionamento feito pela professora sobre o processo de dispersão (turnos de fala 852 e 853): quando as partículas dos pesticidas entram em contato com as partículas de ar, elas não sofrem nenhuma modificação em sua estrutura, "vai continuar sendo bom ar".

\section{Conclusões}

No desenvolvimento da SD proposta, os estudantes forneceram indícios de compreender o processo de dispersão como o espalhamento das partículas dos pesticidas no ar, o qual envolve a movimentação e os choques das mesmas. Esses aspectos são coerentes com o conceito científico de difusão, definido como um processo que consiste na dispersão gradual de uma substância na região ocupada por outra substância, ocasionado por colisões de suas partículas enquanto elas se movem (Atkins e Jones, 2012).

Ao analisarmos os dados, identificamos alguns fatores que foram essenciais para o entendimento dos estudantes sobre o conceito de dispersão durante a SD: o caráter colaborativo das atividades e do grupo; os questionamentos da professora e das pesquisadoras; e o uso de modelos e analogias como ferramentas de pensamento.

Nos trechos dos diálogos apresentados na seção anterior é possível ter indícios da participação ativa dos estudantes em cada uma das etapas da Modelagem Analógica. Isso realça o caráter dialógico e colaborativo dessas atividades, destacado por autores como Mortimer e Scott (2003) e Jiménez-Aleixandre (2010) como necessário para que os estudantes se engajem no processo de aprendizagem de Ciências.

Nos momentos em que, por exemplo, a professora e as pesquisadoras questionaram os estudantes quanto à quantidade de partículas de ar; quanto ao significado do palitinho entre as bolinhas de isopor; e em que ocorreu a inserção de novos dados como a massa molar e a volatilidade dos pesticidas, conseguimos identificar que eles testaram suas ideias e reformularam seus modelos e analogias de forma mais coerente com o conceito científico. Em resposta ao primeiro questionamento mencionado, os estudantes refletiram sobre a representação elaborada por eles, que continha apenas uma bolinha de isopor, e passaram a representar uma maior quantidade delas em referência às inúmeras partículas de ar. Em resposta ao segundo questionamento mencionado, eles passaram refletir sobre a ideia de reação química presente em sua representação e desconectaram as bolinhas de isopor, indicando que reconheciam a existência de interações mais fracas entre as partículas do pesticida e do ar. Com relação à inserção de novos dados, eles levaram em consideração em sua comparação com os diferentes tipos de odorizadores - além das ideias que já haviam expressado sobre a movimentação, choques e espalhamento das partículas dos pesticidas - a relação entre a massa molar e a velocidade das mesmas.

Vale ressaltar a importância dos questionamentos da professora e das pesquisadoras realizados durante todo o processo, como os mencionados nos exemplos anteriores. Conforme evidenciam os trabalhos de Andrade e Mozzer (2016) e Andrade et al. (2017), os questionamentos dos professores auxiliam os estudantes na atribuição e negociação de significados de conhecimentos científicos. Isso também pôde ser identificado nos diálogos apresentados neste trabalho.

Como Mozzer e Justi (2018), apontamos o uso dos modelos e analogias como ferramentas de pensamento nas atividades de modelagem analógica, uma vez que sua manipulação concreta ou mental possibilitou aos estudantes avançar no entendimento conceitual sobre o processo de dispersão ao longo das etapas vivenciadas.

As etapas de criação e expressão dos modelos e analogias proporcionaram à professora, às pesquisadoras e aos pares acesso às ideias que embasavam o entendimento dos estudantes sobre o processo de dispersão; como aquelas sobre a constituição do ar expressa a partir dos modelos da Figura 2 e sobre a relação entre a massa das partículas de pesticida e sua volatilidade, expressa na analogia do Quadro 2. Os estudantes foram conduzidos a analisar suas ideias frente a novas informações, explicações e evidências em diferentes etapas de teste dos modelos e analogias propostos. Por exemplo, a mencionada análise da adequação do modelo da Figura 3 para representar a interação entre as partículas dos pesticidas a partir da reflexão sobre o conceito de reação química levou os estudantes a reformular o modelo, conforme indica a Figura 4. A etapa de avaliação, que neste recorte se deu em relação às limitações das analogias propostas, possibilitou aos estudantes considerar a adequação de suas ideias frente aos objetivos iniciais estabelecidos para criação das comparações e, como consequência, aprimorar seus entendimentos sobre o domínio alvo. Por exemplo, a seleção da limitação referente à diferença de comportamento das partículas do análogo e do alvo em função da velocidade de movimentação das partículas de ar e a desconsideração da limitação referente à diferença de toxicidade das substâncias dos domínios comparados (vide Quadros 1 e 2) foram indicativas da evolução na compreensão dos estudantes sobre o processo de dispersão no nível submicroscópico.

Os fatores identificados nesta pesquisa que contribuíram para o entendimento dos estudantes sobre o conceito de dispersão justificam a importância da proposta de Modelagem Analógica no ensino de Ciências de Mozzer e Justi (2018) para a elaboração de significados sobre conhecimentos científicos (dimensão conceitual). O desenvolvimento de entendimentos pelos estudantes nas dimensões procedimentais e atitudinais, embora não constitua o foco de investigação deste trabalho, também foi indiciado por esse recorte. A dimensão procedimental, por exemplo, está associada às ações dos estudantes de interpretar informações e dados sobre volatilidade, solubilidade e persistência, de reformular os modelos e analogias propostos e de identificar suas limitações. A 
dimensão atitudinal, por exemplo, foi indiciada na colaboração dos estudantes com os pares, no interesse frente à elaboração de significados, na participação das atividades e no posicionamento perante as ideias em discussão. O desenvolvimento de entendimentos nessas dimensões pelos estudantes tem sido explorado em nossa pesquisa mais ampla, e nos fornecem motivos adicionais para defender as implicações do ensino fundamentado na modelagem analógica e na abordagem de QSC para uma aprendizagem de Ciências voltada para o letramento científico.

\section{Agradecimentos}

\section{CNPq, FAPEMIG e UFOP}

\section{Notas}

${ }^{1}$ Conjunturas de relevância na vida cotidiana dos estudantes e que são referentes a alguma problemática relacionada às dimensões mencionadas anteriormente ou a uma combinação destas (Aikenhead, 1985).

${ }^{2} \mathrm{Em}$ trabalhos atuais não temos utilizado o termo pesticida, devido à carga valorativa da palavra, que aporta aos insetos a qualidade de "pestes". Em seu lugar, utilizamos a palavra 'agroquímico'.

${ }^{3} \mathrm{http}: / /$ portalms.saude.gov.br/boletins-epidemiologicos, acessado em Fevereiro 2019.

${ }^{4}$ Óleos essenciais são definidos pela International Standard Organization (ISO) como óleos voláteis, obtidos de partes de plantas por meio de destilação com vapor d'água ou de pressão (Vasconcelos et al., 2011).

${ }^{5}$ Durante o desenvolvimento da SD houve um remanejamento de estudantes entre os grupos; por isso, alguns grupos ficaram com mais integrantes que outros. Isso ocorreu por solicitação dos estudantes, devido às afinidades entre eles.

${ }^{6}$ Fonte: Agência CNM, com informação da Agência Brasil. Trecho da reportagem do site Notícias do Cerrado, publicada no dia 30 de julho de 2016. Disponível em http://agenciabrasil. ebc.com.br/geral/noticia/2016-06/entidades-criticam-leique-autoriza-pulverizacao-aerea-de-inseticida, acessado em Fevereiro 2019.

\section{Referências}

AIKENHEAD, G. S. Collective decision making in the social context of science. Science Education, v. 69, p. 453-475, 1985.

AL-BALUSHI, S. M. The effect of different textual narrations on students' explanations at the submicroscopic level in chemistry. Eurasia Journal of Mathematics, Science \& Technology Education, v. 9, n. 1, p. 3-10, 2013.

ANDRADE, G. M. P. C. e MOZZER, N. B. Análise dos questionamentos do professor em atividades fundamentadas em modelagem analógica. Revista Brasileira de Pesquisa em Educação em Ciências, v. 16, n. 3, p. 825-850, 2016. e Proposta de uma sequência didática sobre o uso de pesticidas fundamentada na modelagem analógica. In: Anais do XI Encontro Nacional de Pesquisa em Educação em Ciências. Florianópolis, SC, 2017.

e OLIVEIRA, T. M. A. O papel dos questionamentos do professor em atividades fundamentadas em modelagem analógica. Enseñanza de Las Ciencias, v. extra, p. 4535-4540, 2017.

ATKINS, P. e JONES, L. Princípios de química: questionando a vida moderna e o meio ambiente. Porto Alegre: Bookman, 2012.

BOGDAN, R. C. e BIKLEN, S. K. Investigação qualitativa em educação: uma introdução à teoria e aos métodos. Porto: Porto Editora, 1994.

BRAGA, I. A. e VALLE, D. Aedes aegypti: inseticidas, mecanismos de ação e resistência. Epidemiologia e Serviços de Saúde, v. 16, n. 4, p. 279-293, 2007.

CAMPOS, J. e ANDRADE, C. F. S. Susceptibilidade larval de duas populações de Aedes aegypti a inseticidas químicos. Revista Saúde Pública, v. 35, p. 232-236, 2001.

CARVALHO, A. M. P. Uma metodologia de pesquisa para estudar os processos de ensino e aprendizagem em salas de aula. In: SANTOS, F. M. T. e GRECA, I. M. (Eds.). A pesquisa em ensino de ciências no Brasil e suas metodologias. $3^{\text {a }}$ ed. Ijuí: Unijuí, 2011. p. 13-47.

CLEMENT, J. Creative model construction in scientists and students: the role of imagery, analogy and mental simulations. Dordrecht: Springer, 2008.

CONRADO, D. M. Questões sociocientíficas na educação CTSA: contribuições de um modelo teórico para o letramento crítico. Tese (Doutorado em Ensino, Filosofia e História das Ciências). Universidade Federal da Bahia, Salvador, 2017.

; NUNES-NETO, N. e EL-HANI, C. N. Análise de argumentos em uma questão sociocientífica no ensino de biologia. Revista da SBEnBio, n. 9, p. 5522-5534, 2016.

FERNANDEZ, C. e MARCONDES, M. E. R. Concepções dos estudantes sobre ligação química. Química Nova na Escola, n. 24, p. 20-24, 2006.

FURTADO, R. F.; LIMA, M. G. A.; NETO, M. A.; BEZERRA, J. N. S. e SILVA, M. G. V. Atividade larvicida de óleos essenciais contra Aedes aegypti. Neotropical Entomology, v. 34, p. 843-847, 2005.

GARCEZ, W. S.; GARCEZ, F. R.; SILVA, L. M. G. E. e SARMENTO, U. C. Substâncias de origem vegetal com atividade larvicida contra Aedes aegypti. Revista Virtual de Química, v. 5, n. 3, p. 363-393, 2013.

GENTNER, D. The mechanisms of analogical learning. In: VOSNIADOU, S. e ORTONY, A. (Eds.). Similarity and analogical reasoning. Cambridge: Cambridge University Press, 1989, p. 199-241.

GILBERT, J. e JUSTI, R. Modelling-based teaching science education. Basel: Springer International Publishing, 2016.

GRACE, M. Teaching citizenship through science: socio-scientific issues as an important component of citizenship. Prospero, v. 12, n. 3, p. 42-53, 2006.

JIMÉNEZ-ALEIXANDRE, M. P. La argumentación sociocientífica contribuye al pensamiento crítico. In: 10 ideas clave: competencias en argumentación y uso de pruebas. Barcelona: Graó, 2010, p. 121133. 
e AGRASO, M. F. A argumentação sobre questões sociocientíficas: processos de construção e justificação do conhecimento na sala de aula. Educação em Revista, v. 43, p. 13-33, 2006.

JUSTI, R. La enseñanza de ciencias basada en la elaboración de modelos. Enseñanza de las Ciencias, v. 24, n. 2, p. 173-184, 2006.

e GILBERT, J. Modelling, teachers'view on the nature of modelling, and implications for the education of modellers. International Journal of Science Education, v. 24, n. 4, p. 369-387, 2002.

KIND, V. Más allá de las apariencias - ideas previas de los estudiantes sobre conceptos básicos de química. México: Editorial Santillana, 2004.

KNUUTTILA, T. Models as epistemic artefacts: toward a nonrepresentationalist account of scientific representation. Helsinki: University of Helsinki, 2005.

LOPES, R. M.; FILHO, M. V. S.; MARSDEN, M. e ALVES, N. G. Aprendizagem baseada em problemas: uma experiência no ensino de química toxicológica. Química Nova, v. 34, n. 7, p. 1275-1280, 2011.

MAMEDE, M. e ZIMMERMANN, E. Letramento científico e CTS na formação de professores para o ensino de ciências. Enseñanza de Las Ciencias, n. extra, VII Congreso, p.1-4, 2005.

MELO, M. S. e SILVA, R. R. A interação entre conceitos cotidianos e científicos no ensino do tema atmosfera. In: Anais do XI Encontro Nacional de Pesquisa em Educação em Ciências. Florianópolis, SC, 2017.

MONTANHA, F. P. e PIMPÃO, C. T. Efeitos toxicológicos de piretróides (cipermetrina e deltametrina) em peixes - revisão. Revista Científica Eletrônica de Medicina Veterinária, n. 18, p. 1-58, 2012.

MORRISON, M. e MORGAN, M. S. Models as mediating instruments. In: MORGAN, M. S. e MORRISON, M. (Eds.). Models as mediators: perspectives on natural and social science. Cambridge: Cambridge University Press, 1999, p. 10-37.

MORTIMER, E. F. e MIRANDA, L. C. Transformações - concepções de estudantes sobre reações químicas. Química Nova na Escola, n. 2, p. 23-26, 1995.

e SCOTT, P. H. Meaning making in secondary science classrooms. Philadelphia: Open University Press, 2003.

MOZZER, N. B. O entendimento conceitual do processo de dissolução a partir da elaboração de modelos e sob a perspectiva da teoria de campos conceituais. Tese (Doutorado em Educação). Universidade Federal de Minas Gerais, Belo Horizonte, 2013

e JUSTI, R. Introdução ao tema dissolução através da elaboração de analogias pelos alunos fundamentada na modelagem. In: Anais do VII Encontro Nacional de Pesquisa em Ensino de Ciências. Florianópolis, SC, 2009.

e ___ Modelagem analógica no ensino de ciências. Investigações em Ensino de Ciências, v. 23, n. 1, p. 155-182, 2018.

NAKHLEH, M. B. Why some students don't learn chemistry: chemical misconceptions. Journal of Chemical Education, v. 69, n. 3, p. 191196, 1992.

NERSESSIAN, N. J. The cognitive basis of model-based reasoning in science. In: CARRUTHERS, P.; STICH, S. e SIEGAL, M. (Eds.).
The cognitive basis of science. Cambridge: Cambridge University Press, 2002, p. 133-153.

PEIXOTO, S. C. Estudo da estabilidade a campo dos pesticidas carbofurano e quincloraque em água de lavoura de arroz irrigado empregando SPE e HPLC-DAD. Dissertação (Mestrado em Química). Universidade Federal de Santa Maria, Santa Maria, 2007.

PETERSON, R. F. e TREAGUST, D. F. Grade-12 students' misconceptions of covalent bonding and structure. Journal of Chemical Education, v. 66, n. 6, p. 459-460, 1989.

PRETI, D. Entre o oral e o escrito: a transcrição de gravações. In: Oralidade em textos escritos. São Paulo: Humanitas, 2009, p. $303-$ 326.

. O discurso oral culto. $2^{\text {a }}$ ed. São Paulo: Humanitas, 1999.

QUADROS, A. L.; CRUZ, M. L. F.; BARCELOS, A. S.; CARMO, N. H. S. e SANTOS, B. F. As relações sociais que regulam a prática docente no ensino de ligações químicas. Chemical Education in Point of View, v. 1, n. 1, p. 144-166, 2017.

QUEIROZ, A. S. Contribuições do ensino de ligação iônica baseado em modelagem ao desenvolvimento da capacidade de visualização. Dissertação (Mestrado em Educação). Universidade Federal de Minas Gerais, Belo Horizonte, 2009.

RAPPOPORT, L. T. e ASHKENAZI, G. Connecting levels of representation: emergent versus submergent perspective. International Journal of Science Education, v. 30, n. 12, p. 15851603, 2008.

SADLER, T. D. Situating socio-scientific issues in classrooms as a means of achieving goals of science education. In: SADLER, T. D. (Ed.). Socio-scientific issues in the classroom. Dordrecht: Springer, 2011, p. 1-9.

CHAMBERS, F. W. e ZEIDLER, D. L. Student conceptualizations of the nature of science in response to a socioscientific issue. International Journal of Science Education, v. 26, n. 4, p. 387-409, 2004.

SANTOS, W. L. P. e MORTIMER, E. F. Tomada de decisão para ação social responsável no ensino de ciências. Ciência \& Educação, v. 7, n. 1, p. 95-111, 2001.

SILVA, E. L. e MARCONDES, M. E. R. Visões de contextualização de professores de química na elaboração de seus próprios materiais didáticos. Revista Ensaio, v. 12, n. 1, p. 101-118, 2010.

TORRES, N. e SOLBES, J. Pensamiento crítico desde cuestiones sociocientíficas. In: CONRADO, D. M. e NETO, N. N. (Eds.). Questões sociocientíficas: fundamentos, propostas de ensino e perspectivas para ações sociopolíticas. Salvador: EDUFBA, 2018, p. 59-76.

VASCONCELOS, M. A. M.; ALVES, S. M.; SOUZA FILHO, A. P. S.; FIGUEIRÊDO, F. J. C. e CUNHA, R. L. Extração do óleo essencial de folhas e galhos de oriza (Pogostemon heyneanus Benth.). Comunicado Técnico 277. Belém: Embrapa, 2011.

ZABALA, A. A prática educativa: como ensinar. Porto Alegre: Artmed, 1998.

ZEIDLER, D. L.; SADLER, T. D.; SIMMONS, M. L. e HOWES, E. V. Beyond STS: a research-based framework for socioscientific issues education. Science Education, v. 89, n. 3, p. 357-377, 2005. 


\section{Resenha}

\section{Estudos de Caso para o Ensino de Química 2 Por: Mara E. Fortes Braibante (Departamento de Química/Universidade Federal de Santa Maria)}

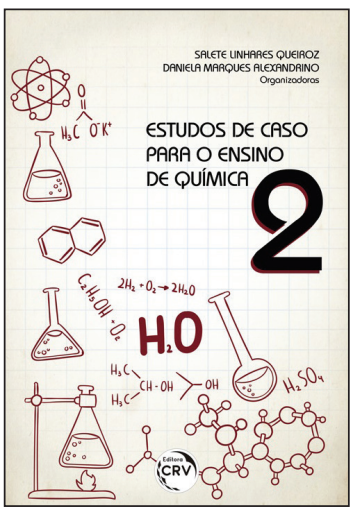

O livro "Estudos de Caso para o Ensino de Química 2", organizado por Salete Linhares Queiroz (USP) e Daniela Marques Alexandrino (UESB), publicado recentemente pela Editora CRV, constitui-se em uma importante referência para o Ensino de Química. Estudos de caso são histórias com uma determinada mensagem, não são simples narrativas para entretenimento, são histórias "casos" apresentadas a estudantes com a finalidade de facilitar a aprendizagem. O livro apresenta 11 capítulos, sendo que os capítulos 2 ao 11 contêm um material didático interessante e instigante na forma de casos elaborados por mestrandos e doutorandos, egressos de disciplina ministrada pela Professora Salete Linhares Queiroz. O capítulo 1 desta obra discorre sobre a inserção e popularização desta metodologia no Ensino de Química no Brasil, cuja pioneira foi a referida Professora. O diferencial desta obra, a exemplo do primeiro volume "Estudos de Caso para o Ensino de Química 1", é a forma como cada caso é explorado, além de serem casos originais e inspiradores, apresentam apontamentos didáticos, cujos autores subsidiam o leitor discutindo o contexto em que cada caso está inserido. No item Características e contextualização do tema, cada capítulo apresenta as características de cada caso, atendendo aos critérios de Herreid (J. Coll. Sci. Teach., 2016), tais como, é um caso estruturado, curto, inclui diálogos, desperta interesse pela temática abordada, suscita discussões, dentre outros critérios citados e utilizados. Além de ser discutida a utilidade pedagógica dos casos, é apresentada uma contextualização rica sobre o tema abordado, servindo de referência para que professores de todos os níveis de ensino, bem como professores em formação, possam utilizá-los em suas práticas educativas. Ao ler cada caso percebe-se em cada item o cuidado com que foram elaborados. As Fontes de inspiração na produção do caso, citadas na obra, que levaram os autores a elaborar as narrativas foram diversas, desde capítulo de livros, notícias publicadas em jornais até a própria experiência de vida de cada um deles, constituem-se em um tópico muito interessante, sendo também inspirador para o leitor que pretende utilizar este método para dinamizar suas aulas. No item Soluções para o caso e conteúdos de Química em pauta, os autores orientam o leitor para a resolução do estudo de caso, finalizando cada capítulo com um rico referencial.

No Ensino de Química o método de Estudos de caso demanda a relação de dois componentes básicos: a informação química e o contexto social, neste sentido as narrativas deste livro trazem de forma primorosa estes dois componentes. O Capítulo 2 Transgênico e transgênero? aborda questões sociocientíficas relacionadas a alimentos transgênicos, pesticidas e meio ambiente, sem contar com o trocadilho que leva à discussão de uma reação química, a conversão da testosterona em estradiol, a partir da detecção da diminuição na procriação em um ranário. É um caso instigante, não requerendo uma solução, mas sim provoca no leitor uma reflexão sobre quais as causas que provocaram tal fato, incentivando a pesquisa. Dependendo das propostas encontradas para explicar as causas, conteúdos de Química e Bioquímica podem ser explorados. Alguns capítulos, como o 3, intitulado Mirou errou, foi diagnosticado!, além dos conteúdos necessários para a resolução do estudo de caso, como os adoçantes, sua composição e estrutura química, traz sugestões dos autores sobre outros conteúdos de Química que podem ser abordados com o mesmo estudo de caso, o que amplia a sua aplicação. As Diretrizes Curriculares Nacionais Gerais sugerem propostas interdisciplinares na organização curricular, não bastando somente uma integração de conteúdos, sendo necessário também o envolvimento do professor em atitudes interdisciplinares. Neste contexto os estudos de caso apresentados permitem que o leitor estabeleça diversas relações, favorecendo atitudes interdisciplinares. Empolgada com a leitura de cada estudo de caso, sobre as questões ambientais relatadas, éticas, relações sugeridas em diversas áreas e os conteúdos científicos que emergem de cada capítulo, 'quase' não deixo para os leitores a leitura prazerosa e análise dos demais capítulos. Embalados na sacola, Do coco eu quero a casca, E se os pássaros tomassem antidepressivos? Luz cores e confusão, $O$ aroma de seus sonhos, A loira perigosa, Contaminação nas águas do Rio Paraíba: a quem será que se destina e A carne lânguida são as demais narrativas que compõem este livro, todas muito interessante, baseadas em fatos reais ou imaginários que fazem com que sua leitura seja agradável. Desta forma recomendo fortemente esta obra que possibilita vários olhares sobre cada estudo de caso, mesmo que possuam estruturas semelhantes, o livro abre um leque imenso de possibilidades para serem aplicadas no Ensino de Química, suscitando reflexão, discussão, interdisciplinaridade e formação cidadã, não abandonando a metodologia científica.

Salete Linhares Queiroz e Daniela Marques Alexandrino (Orgs.). Estudos de Caso para o Ensino de Química 2. Editora CRV, 2018. 152 páginas. ISBN:978-85-444-2862-7. DOI: 10.24824/978854442862.7 